\title{
The application of linkage analysis to genetic counselling in families with Duchenne or Becker muscular dystrophy
}

\author{
SHIRLEY HODGSON, ALISON WALKER, CHARLOTTE COLE, \\ KEVIN HART, LYNN JOHNSON, JOHN HECKMATT*, \\ VICTOR DUBOWITZ*, AND MARTIN BOBROW \\ From the Paediatric Research Unit, United Medical and Dental Schools of Guy's and St Thomas's Hospitals, \\ Guy's Tower, London Bridge SE1 9RT; and *the Department of Paediatrics and Neonatal Medicine, $\stackrel{\text { N }}{+}$ \\ Hammersmith Hospital, Ducane Road, London W12 OHS.
}

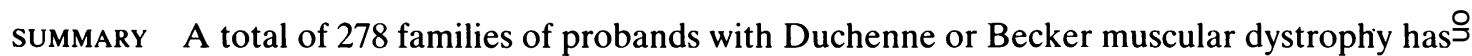
been ascertained and offered genetic counselling. Linkage studies have been performed in these $\vec{z}$ families using polymorphic DNA markers identifying loci linked to Duchenne and Becker⿳亠 muscular dystrophy. The clinical features of the probands are discussed: there was markedô intrafamilial resemblance in the severity of the disease.

We estimate that a complete study of potential carriers in these families would require analysis of samples from approximately 1400 subjects. The results of linkage studies tended to move women's carrier risk estimates (based on $\mathrm{CK}$ and pedigree data) towards the extremes of the risk요 categories, providing a more definitive risk estimate for $81 \%$ of the women who were previously⿳亠二口犬 in the middle range of carrier risk probabilities. About $70 \%$ of the families had only one affected member. Linkage analysis altered carrier risk estimates in $95 \%$ of sisters and aunts of index cases, $\underset{\Omega}{\mathbb{Q}}$ but only affected estimates of the mother's carrier risks in about $11 \%$ of isolated cases. Even $\overrightarrow{\vec{F}}$ where linkage studies were not helpful in elucidating carrier risks, information could usually be 3 obtained for use in prenatal diagnosis if required.

We have assessed the attitudes to pregnancy and prenatal diagnosis of women at risk of being? carriers of Duchenne or Becker muscular dystrophy and report 17 pregnancies in these women.

Duchenne muscular dystrophy (DMD) is the commonest and most severe type of dystrophy, inherited as an $\mathrm{X}$ linked recessive trait, with an incidence of about 1 in 3000 to 3500 males. ${ }^{1}$ Becker muscular dystrophy (BMD) has a similar clinical pattern, but is milder than DMD and between six and 10 times less frequent. About half the males affected with DMD have delayed motor milestones. Pelvic girdle weakness develops gradually, with loss of ambulation by about 11 years of age. Pectoral girdle and distal arm and leg weakness develop progressively and survival much beyond the age of 20 years is unusual. Calf hypertrophy is common, but associated dysmorphic features are not found. Mild mental retardation may occur and ECG abnormalities are common. Creatine kinase (CK) levels are

Received for publication 12 June 1986.

Revised version accepted for publication 23 October 1986. greatly raised in DMD. The EMG is myopathic and muscle biopsy shows characteristic histology. There is no clinical or laboratory finding which distinguishes between DMD and BMD, apart from the milder nature and slower course of BMD. An arbitrary definition is that boys with BMD retain the ability to walk beyond the age of 16 years. ${ }^{2}{ }^{3} \sim$

Because there is as yet no treatment for thesen disorders, genetic counselling is of particular im portance for females at risk of being carriers. The $y_{0}^{\omega}$ can then make informed decisions about childbear ing and whether to avail themselves of prenataf diagnosis.

Until recently, carrier detection in female rela tives of boys with DMD or BMD has relied entirelyo upon pedigree analysis ${ }^{4}$ and estimations of serumb CK, with or without EMG and muscle biopsy. These्ष tests can all yield false negative results; for instance? one third of obligate carriers of DMD have serume 
CK levels within the normal range. ${ }^{5}$ The discovery of polymorphic loci linked to $D M D$ and $B M D$ offers an additional means of defining carrier risks within families and is also, in principle, applicable to prenatal diagnosis. ${ }^{6}$ Fetal sex can now be determined at chorion biopsy in the first trimester of pregnancy and DNA analysis may be performed on the chorionic villus samples (CVS) obtained by this technique.

To explore the application of linkage techniques to genetic counselling, we approached the families of patients with $\mathrm{X}$ linked muscular dystrophies currently attending the Hammersmith Hospital Muscle Clinic and the South-East Thames Regional Genetics Centre, Guy's Hospital. We hoped that previous education, by counselling of a large body of families at risk, would lead to a more rational approach to the clinical use of linked markers for prenatal diagnosis and carrier risk estimates. The uptake of genetic advice, the problems encountered in setting up this service, and the effects of counselling on women's attitudes towards pregnancy will be discussed.

\section{Methods}

POPULATION STUDIED

In the initial part of the study, we ascertained all the DMD and BMD families who had attended the Hammersmith Hospital Paediatric Department in recent years and those attending the Paediatric Research Unit, Guy's Hospital, a total of 318 DMD and 59 BMD families. A letter was sent to the 213 families attending the Hammersmith Hospital Clinic at present, explaining the project and offering genetic counselling services. Subsequently, families who had attended the South-East Thames Regional Genetics Centre at Guy's Hospital were also contacted.

Those families consenting to participate were seen, counselled, and blood was taken, where possible, from the index case and his mother, for DNA and CK analysis. Further blood samples were taken from females in the families who required genetic counselling and from males, such as normal brothers, the father, and the uncles of the index case, who could provide phase information for counselling. If there was a positive family history of muscular dystrophy, more extensive family studies were undertaken.

We have personally seen 236 DMD and 42 BMD families from among the patients attending the Hammersmith Hospital, and the South-East Thames Regional Genetics Centre and the Department of Paediatric Neurology, both at Guy's Hospital. The probands were examined by at least one of the authors. We took pedigree information and confirmed the diagnosis on the basis of history, physical examination, serum creatine kinase levels, EMG, and muscle biopsy results. ${ }^{7}$ Not all families contained a living affected male who was available for sampling. Blood was taken from 181 boys with DMD, 34 males with BMD, and 823 relatives, for DNA studies.

CREATINE KINASE ESTIMATIONS

Creatine kinase activity was assayed at the Hammersmith Hospital by the Scandinavian recommended method ${ }^{8}$ and results were based, where possible, on the average of three separate blood samples from each subject. Likelihood ratios were calculated from the values obtained from obligate carriers of DMD and those obtained from normal women, and these were combined with the pedigree data using a Bayesian calculation, to give a combined risk for a woman of being a carrier of muscular dystrophy. ${ }^{9}$

RIS K CALCULATIONS

Carrier risk estimates combining linkage data with CK levels were calculated either by hand or using the computer programme RISKDNA, which integrates information from DNA markers with pedigree and CK data. ${ }^{10}$

DNA ANALYSIS

DNA was extracted from whole blood ${ }^{11}$ and digested with relevant restriction endonucleases. After electrophoresis and Southern blotting, ${ }^{12}$ filters were hybridised with appropriate ${ }^{32} \mathrm{P}$ labelled DNA probes. Details of the loci tested, the probes used, and the heterozygote frequencies we observed are listed in table 1.13

Our strategy for the use of DNA probes for genetic counselling is as follows. For carrier detection, we screened for heterozygosity in a female, often the mother of the proband, using DNA markers in the following order: (1) pERT87-1 and pERT87-15, using an XmnI digest. (2) pXJ1.1 and pERT87-15, using a TaqI digest. (3) pERT87-8, using a BstXI digest. (4) pERT87-1, using BstNI and pERT87-8, using TaqI. When the woman was found to be heterozygous at a locus defined by one of these probes, this was used for analysis of her family.

Where flanking DNA markers were available, these were used preferentially. However, information using markers pXJ1.1 and pERT87 alone, with an estimated recombination fraction of 0.05 with the $D M D$ and $B M D$ loci, ${ }^{15}$ made substantial differences to carrier risk estimates and was an efficient first screen. 
TABLE 1 Details of the DNA probes used.

\begin{tabular}{|c|c|c|c|c|c|}
\hline Locus & Probe & $\begin{array}{l}\text { Restriction } \\
\text { enzyme }\end{array}$ & $\begin{array}{l}\text { Recombination } \\
\text { fraction used } \\
\text { for counselling }\end{array}$ & $\begin{array}{l}\text { Observed } \\
\text { heterozygote } \\
\text { frequency }(\%)\end{array}$ & Reference \\
\hline$D X S 164$ & $\begin{array}{l}\text { pERT 87-15 } \\
\text { pERT87-8 } \\
\text { pERT87-1 }\end{array}$ & $\begin{array}{l}\text { TaqI } \\
\text { BstXI } \\
\text { XmnI }\end{array}$ & 0.05 & $\left.\begin{array}{l}37 \cdot 2 \\
40 \cdot 6 \\
36 \cdot 2\end{array}\right\}$ & 15 \\
\hline$D X S 84$ & 754 & PstI & $0 \cdot 16$ & $50 \cdot 0$ & 17 \\
\hline DXS28 & $\mathrm{C7}$ & EcoRV & 0.12 & 34.4 & 18 \\
\hline$D X S 7$ & $\mathrm{Ll} \cdot 28$ & TaqI & 0.20 & $40 \cdot 2$ & 19 \\
\hline
\end{tabular}

Screening of mothers wishing prenatal diagnosis was performed using the above markers, closely linked to $D M D$ and $B M D$, and, in addition, the flanking markers 754 and 99.6 (using Pst $\mathrm{I}$ ), C7 (using EcoRV), and RC8 and L1.28 (using TaqI). Prenatal diagnoses were performed on DNA extracted from chorionic villus samples, using the closest marker (pXJ1.1 or pERT87) informative in the mother, and the two closest informative flanking markers.

Close flanking DNA markers $(754,99 \cdot 6$, and C7) were used preferentially for prenatal diagnosis, but where a woman presented late in pregnancy, prenatal advice was sometimes given using only the closely linked DNA probes pERT87 and pXJ1.1. Risk estimates and the possibility of inaccurate diagnosis using linked DNA markers were fully discussed with the families concerned, and decisions based on this advice were taken in full cognisance of the accuracy of the tests used in each case.

\section{Results}

\section{UPTAKE RATES}

Our 213 initial letters drew responses from 94 families. Of these, 80 indicated their willingness to participate in the study and 14 families within this group asked for urgent genetic counselling. A further 14 families declined to take part in the studies. Despite this moderate initial response, virtually all of the families who had not replied to the questionnaire, as well as half of those initially declining to participate, were subsequently seen for counselling and testing. An additional 72 families were later recruited, totalling 236 DMD and 42 BMD families.

\section{STRUCTURE OF FAMILIES}

The family structures of all 318 DMD and 59 BMD families known to us are shown in tables 2 and 3 . A total of $23 \%$ of DMD index cases and $32 \%$ of BMD cases were familial. In $82 \%$ of DMD cases and $78 \%$ of BMD cases, there were close female relatives, other than the mothers of the index cases, who might require genetic counselling.

Of the 278 families seen personally in this study, $28 \%$ of $236 \mathrm{DMD}$ index cases and $33 \%$ of 42 BMD cases were familial. In these families, the mean number of sibs of the DMD index cases was $1 \cdot 59 \pm 1 \cdot 34$, and of the BMD index cases $1 \cdot 84 \pm 1 \cdot 46$.

TABLE 2 Structure of families initially ascertained.

\begin{tabular}{|c|c|c|}
\hline & $D M D$ & $B M D$ \\
\hline \multicolumn{3}{|l|}{ Total clinic population } \\
\hline (No of families) & (318) & (59) \\
\hline \multicolumn{3}{|l|}{ Multiple affected males } \\
\hline (10 index cases dead) & $23 \%$ & $32 \%$ \\
\hline \multicolumn{3}{|l|}{ Isolated case with unaffected brother } \\
\hline (10 index cases dead) & $33 \%$ & $24 \%$ \\
\hline Isolated case without brother & $41 \%$ & $44 \%$ \\
\hline Dead isolated case without brother & $3 \%$ & - \\
\hline \multicolumn{3}{|l|}{ Families personally seen } \\
\hline (No of families) & (236) & $(42)$ \\
\hline Multiple affected males ( 8 dead) & $28 \%$ & $33 \%$ \\
\hline \multicolumn{3}{|l|}{ Isolated case with unaffected brother } \\
\hline ( 7 index cases dead) & $30 \%$ & $28 \%$ \\
\hline Isolated case without brother & $39 \%$ & $39 \%$ \\
\hline Dead isolated case without bfother & $3 \%$ & - \\
\hline
\end{tabular}

TABLE 3 Female relatives of affected boys.

Total clinic population

318 families with Duchenne muscular dystrophy

$61 \%$ had sisters

$54 \%$ had aunts

Total No of sisters/aunts $=708$

59 families with Becker muscular dystrophy

$68 \%$ had sisters

$49 \%$ had aunts

Total No of sisters/aunts $=120$

Families seen personally in this study

236 families with Duchenne muscular dystrophy

$61 \%$ had sisters

$68.6 \%$ had aunts

Total No of sisters/aunts $=402$

42 families with Becker muscular dystrophy

$\mathbf{4 7} \cdot \mathbf{6} \%$ had sisters

$59.5 \%$ had aunts

Total No of sisters/aunts $=84$ 
CLINICAL DETAILS (TABLE 4)

None of the affected boys had dysmorphic features. Many boys with DMD had speech delay and required specific therapy for this. Mental retardation was found in $29 \%$ of DMD (table 4 ), but was not found in BMD, in accordance with previous experience. ${ }^{1}$ Of DMD boys with mental retardation, the average age at which ambulation was lost was $9 \cdot 8 \pm 1.54$ years old; in the group with normal IQ, this was $9.6 \pm 1.5$ years old. Fifteen boys lost ambulation between the ages of 13 and 17 years, and were thus in the intermediate range between DMD and BMD.

In 18 pairs of brothers with DMD where intelligence was assessed, two pairs of affected boys both had mental retardation, while the 16 other pairs of brothers were all of normal intelligence. One family of three brothers (aged four years and younger) with muscular dystrophy all had speech and developmental delay. Their uncle, who had DMD, had an IQ of 50 .

The clinical courses in two or more brothers, or more distant relatives, affected with DMD or BMD, were similar in 28 out of 30 families where detailed information was available.

In one family the uncle of the index case lost ambulation at 17 years of age and was alive, in a wheelchair, at 40 years of age, while the index case has a disorder more suggestive of DMD. However, as he is still only seven years old, his clinical course cannot be predicted. One pair of brothers had slightly discordant courses, in that one brother walked at 18 months and ceased to walk at 12 years, while the other walked at 12 months and ceased to walk at 16 years. Both had speech delay. Even in these cases, the discrepancies noted were not marked.

In an additional pair of brothers there was a striking difference in clinical symptoms, where one brother had classical DMD and ceased to walk at six and a half years, but the other had minimal proximal hip girdle weakness at 15 years, despite a high serum $\mathrm{CK}$ level. The mildly affected brother showed

TABLE 4 Clinical details of affected boys.

\begin{tabular}{lll}
\hline & $D M D$ & $B M D$ \\
\hline \% learning to walk below & $50 \%$ & $62 \cdot 8 \%$ \\
age of 18 months & $\mathrm{n}=188$ & $\mathrm{n}=43$ \\
Mean age of loss of ability & $9 \cdot 5 \pm 1 \cdot 75$ & $23 \cdot 2 \pm 11 \cdot 2^{*}$ \\
to walk (year) & $\mathrm{n}=148$ & $\mathrm{n}=6$ \\
Mean age at first recorded & $2 \cdot 5 \pm 1 \cdot 12$ & $2 \cdot 3 \pm 0 \cdot 85$ \\
use of sentences (year) & $\mathrm{n}=166$ & $\mathrm{n}=32$ \\
Mental retardation & $28 \cdot 7 \%$ & $0 / 17$ \\
(ESN or IQ below 80) & $\mathrm{n}=130$ & \\
\hline
\end{tabular}

*36 BMD patients are still ambulant. 26 of whom are below the age of 16 years. The diagnosis of BMD in these cases is based upon their relatively mild clinical features. minimal myopathic changes on muscle biopsy and chromosome analysis revealed the karyotype $47, \mathrm{XXY}$, so that his symptoms were presumed to be features of the manifesting DMD heterozygote (A Walker, 1986, personal communication).

CARRIER RISK ESTIMATES USING LINKAGE

The way in which carrier risk estimates have been altered by the use of linkage analysis in the 113 women where useful information was obtained is shown in the figure. So far, we have studied 52 sisters of affected boys, of whom 28 were sisters of sporadic cases. In only two of these (in families of sporadic cases) was no alteration of risk estimate possible using linkage analysis. A total of 43 aunts of affected boys has been studied, of whom 38 were aunts of sporadic cases, and in only two (both in families of sporadic cases) was no useful linkage information obtained. The carrier risks of 69 obligate carriers were, of course, unaltered by linkage analysis. As has been previously reported, ${ }^{20}$ linkage analysis generally correlates well with high or low risk estimates using pedigree and $\mathrm{CK}$ data, and tends to move the risk estimates towards the extremes of the risk range, leaving fewer women in the ambiguous middle range of risks between 20 and $80 \%$. Of the 113 women represented in the figure, 37 were in this risk range before linkage analysis. After adding linkage data to the risk calculation, only seven women remained in this middle range.

FAMILIES OF SPORADIC CASES

In the $171(72 \cdot 5 \%)$ DMD and $28(66 \cdot 7 \%)$ BMD families where the probands were isolated cases, linkage analysis significantly altered the risk to mothers of probands in three specific situations. In four cases, the proband was found to have a DNA deletion (detected by non-hybridisation of the patient's DNA to subclones of pERT87 or pXJ1. $1^{21}$ ) and his mother was heterozygous at the site detected by the marker for which her affected son was deleted. In these cases, the mother's risk is greatly reduced, as she is clearly not carrying the deletion which is presumed to cause the disease in her son. In practice, because of uncertainty about the precise relationship between the DNA deletion and the DMD mutation, these women were given a low carrier risk estimate, but with some reservations. In five families, the affected boys were found to have inherited the same alleles linked to DMD as their normal brothers, which markedly reduced the likelihood that the mother was a carrier. Conversely, if an affected boy had inherited different alleles from his unaffected brother, this somewhat increased the mother's carrier risk estimate (in five mothers studied). Information about the grandparental ori- 


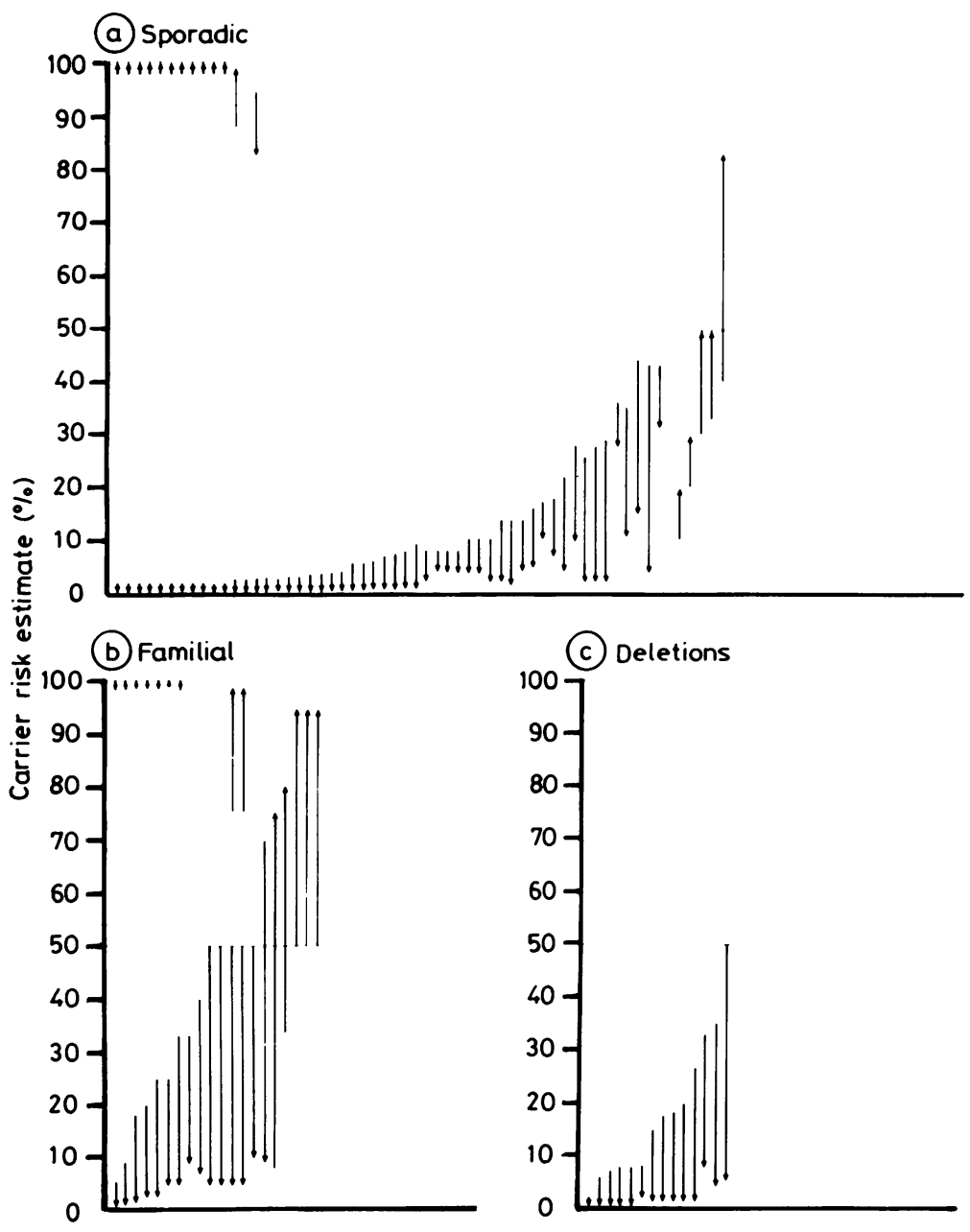

FIGURE The effects of linkage analysis on carrier risk estimates. (a) 70 women from families of sporadic cases of $B M D$ or DMD in whom linkage analysis altered carrier risk estimates.

(b) 29 women from families of familial cases of BMD or DMD in whom linkage analysis altered carrier risk estimates.

(c) 14 women in whom carrier risks were altered, from families of $B M D$ or DMD cases with DNA deletions. Each arrow represents a $@$ woman's carrier risk estimates. The arrow starts at her risk estimate using $C K$ and pedigree data and ends at the risk estimate incorporating DNA linkage data.

gin of the alleles inherited by the affected boy had a small effect on the mother's carrier risk estimate in eight cases; thus, her risk was slightly reduced if the affected boy had inherited the grandpaternal allele. The proportion of $11 \%$ of mothers of isolated cases whose risk estimates were altered with the use of linkage analysis could rise to about $28 \%$ when linkage studies are completed.

Although carrier risks to mothers of sporadic cases were not often greatly altered, linkage information was used to alter carrier risk estimates for sisters and aunts of the proband in these families. We used linkage calculations to alter the carrier risks of 53 sisters of affected boys. ${ }^{22}$ In 15 families where linkage information indicated that the isolated affected boy had inherited his grandpaternal alleles linked to the $D M D$ locus, the probability was 웅 increased that his disease had arisen as a new $\frac{D}{O}$ mutation, either in the grandpaternal or the maternal gamete. Consequently, the risk that the grand- $N$ mother was a carrier was reduced and this, in turn, $N$ reduced the carrier risk estimates for 13 aunts. If, however, the affected boy had inherited the grand- $\omega$ maternal allele, as in nine of our families, the carrier? risks to his aunts depended upon whether or noto they had inherited from their mother the same allele as the mother of the affected boy. This was the case? with seven aunts.

ATTITUDES TO PREGNANCY

Eleven women with carrier risks higher than $20 \% \stackrel{\mathbb{D}}{\varrho}$ decided to have no further children (many opting for 
sterilisation). This is probably an underestimate, because women making this decision do not often seek further genetic advice.

Table 5 shows the decisions of women at risk of being carriers regarding pregnancies before the availability of prenatal diagnosis using linkage analysis.

Women perceiving their carrier risk to be low (below $10 \%$ ) often elected to take the small risk of having an affected son without prenatal diagnosis, but most women with carrier risks above $30 \%$ elected to have fetal sexing and termination of pregnancy if the fetus was found to be male. Occasional exceptions are found: in our series two sisters at very high risk of being carriers both elected to continue their pregnancies without any form of prenatal diagnosis.

We have been asked for prenatal diagnosis or genetic counselling using linkage analysis in relation to 17 pregnancies in 15 women (table 6). Three women (cases 9,10 , and 12) who had their carrier risk estimates substantially reduced by DNA analysis from 50 to $5 \%, 25$ to $2 \%$, and 20 to $2 \%$, respectively, elected to continue their pregnancies without prenatal diagnosis. Two women (cases 13 and 15) had prior carrier risk estimates, on pedigree and $\mathrm{CK}$ data, which they considered low enough $(10 \%$ and $0.5 \%)$ for them to continue their pregnancies without prenatal diagnosis, but DNA studies provided additional reassurance by reducing their carrier risk estimates even further.

Prenatal diagnosis was requested by seven women at high risk of being carriers who were prepared to take a $5 \%$ or smaller risk of having an affected son. Three pregnancies found to be female were continued. Four carrier women (cases 1, 2, 5, and 11) elected to continue pregnancies found to be male with low (5\% or less) risks of being affected, whereas three women (cases 6, 8, and 14) terminated pregnancies found to be male with higher $(48 \%, 28 \%$, and $8 \%)$ risks. It is interesting that case 2 was not prepared to take a $5 \%$ risk of an affected son in her first pregnancy, but was prepared to do so in her second. Case 1 requested prenatal diagnosis in her first pregnancy, but was not heterozygous for any of the markers available at that time. In her second pregnancy, however, one was found, and she is continuing a monochorionic twin pregnancy with

TABLE 5 Decisions about 36 pregnancies in carrier women before the availability of linkage analysis for prenatal diagnosis.

\begin{tabular}{|c|c|c|c|c|c|c|c|}
\hline \multirow[t]{2}{*}{ Intention } & \multicolumn{6}{|l|}{ Risk } & \multirow[t]{2}{*}{ Total } \\
\hline & $0-10 \%$ & $10-20 \%$ & $20-30 \%$ & $30-50 \%$ & $50-75 \%$ & $75-100 \%$ & \\
\hline $\begin{array}{l}\text { Terminate male pregnancy } \\
\text { Keep male pregnancy } \\
\text { Not sure (kept female pregnancy) }\end{array}$ & $\begin{array}{l}1 \\
8\end{array}$ & $\begin{array}{l}2 \\
2\end{array}$ & $\begin{array}{l}2 \\
1 \\
1\end{array}$ & $\begin{array}{l}7 \\
0\end{array}$ & $\begin{array}{l}1 \\
1\end{array}$ & $\begin{array}{l}7 \\
2 \\
1\end{array}$ & $\begin{array}{r}20 \\
14 \\
2\end{array}$ \\
\hline
\end{tabular}

(Two of these were in families with Becker muscular dystrophy.)

TABLE 6 Use of linkage analysis in 17 pregnancies.

\begin{tabular}{|c|c|c|c|c|c|}
\hline $\begin{array}{l}\text { Case } \\
\text { No }\end{array}$ & $\begin{array}{l}\text { Carrier } \\
\text { risk (\%) }\end{array}$ & $\begin{array}{l}\text { Relationship to } \\
\text { affected male }\end{array}$ & $\begin{array}{l}\text { Sex of } \\
\text { fetus }\end{array}$ & $\begin{array}{l}\text { Risk estimate after prenatal diagnosis } \\
(\%)\end{array}$ & Outcome \\
\hline 1 & 100 & Aunt & $\begin{array}{l}M \\
M \text { twins }\end{array}$ & $\begin{array}{l}\text { Not informative } \\
5\end{array}$ & $\begin{array}{l}\text { Terminate } \\
\text { Continue }\end{array}$ \\
\hline 2 & 100 & Sister & $\begin{array}{l}\mathbf{F} \\
\mathbf{M}\end{array}$ & 5 & $\begin{array}{l}\text { Continue } \\
\text { Continue }\end{array}$ \\
\hline 3 & 100 & Sister & $F$ & & Continue \\
\hline 4 & 100 & Sister & $\mathbf{F}$ & & Continue \\
\hline 6 & 50 & Sister (BMD) & $\mathbf{M}$ & 43 & Terminate \\
\hline 7 & $30 \downarrow 3$ & Sister & $\mathbf{M}$ & & Terminate \\
\hline 8 & $50 \downarrow 30$ & Mother & $\mathbf{M}$ & \pm 28 & Terminate \\
\hline 9 & $50 \downarrow 5$ & Sister & $?$ & & Continue \\
\hline 10 & $25 \downarrow 2$ & Sister (severe BMD) & $?$ & & Continue \\
\hline 11 & $20 \downarrow 2$ & Sister & $\mathbf{M}$ & $\pm 0 \cdot 1$ & Continue \\
\hline 12 & $20 \downarrow 2$ & Aunt & $?$ & & Continue \\
\hline 13 & $10 \downarrow v$ low & Aunt & $?$ & & Continue \\
\hline 14 & $8-9$ & Sister & $\mathbf{M}$ & \pm 8 & Terminate \\
\hline
\end{tabular}

Risks in italics obtained by combining linkage analysis with previously available carrier risk estimates. 
an estimated 5\% risk of DMD. At present, 11 of these pregnancies are continuing.

\section{Discussion}

The clinical features of the population of boys with DMD and BMD in this study were not unusual, and there was no case which showed dysmorphic features. No difference was found between the ages at which the DMD boys with mental retardation and those with normal intelligence lost ambulation. Heterogeneity has been suggested in the past, using these parameters, by some authors ${ }^{23}$ but not by others. ${ }^{24}$ The features of DMD and BMD were seen as a spectrum, with some BMD cases quite severely affected. There was considerable clinical resemblance within families, both in the presence or absence of obvious mental handicap and in the general severity of the muscle disease. In the only family in which the disease severity in two brothers differed markedly, one was found to have the chromosome constitution 47,XXY and was presumably a manifesting heterozygote for DMD.

There was an overwhelmingly positive response to our approaches to families for cooperation in family studies, and we have become increasingly involved in providing a genetic counselling service for them. We have already performed restriction fragment length polymorphism (RFLP) analysis on 215 affected males and 823 relatives, and we estimate that there are potentially a further 350 samples to be taken, if we are to complete our analysis of potential carriers in these families. We will therefore analyse in total about 1400 samples from 278 families. This gives an estimate of the workload involved in applying linkage to the analysis of $\mathrm{X}$ linked disorders for genetic counselling, which may be of value in planning further service development.

Our experience with genetic counselling suggests that linkage information provides further reassurance to women at low carrier risks, who may then undertake pregnancies without prenatal diagnosis. Women with higher carrier risks may still prefer to have pregnancies terminated if found to be male, but many may continue a pregnancy if prenatal tests show a male to have a $5 \%$ or lower risk of being affected. In the absence of disease specific prenatal tests, reproductive compensation after termination of male pregnancies probably had the dysgenic effect of increasing the numbers of carrier daughters born. Parents of affected boys appear to have had approximately the same number of children as the general population. The average size of the families we have studied, including the probands, was approximately $2 \cdot 7$. The Registrar General's statistics give family size as varying between 2.0 and 2.3 since 1928. However, our sample includes some sibships of older generations and a few families from $\overrightarrow{\overrightarrow{\mathrm{S}}}$ outside the UK.

Because the current linkage estimates have erro을 rates of the order of 2 to $5 \%$, the most dramatio qualitative change in carrier risk estimates is seen iा women with prior carrier risks in the low to intermediate range. These women had low, but now negligible, risks which they were unwilling to run $\vec{\nabla}$ Dropping these risks by a factor of 20 altered their decisions about whether to undergo pregnanciess without prenatal diagnosis. Linkage studies signifi cantly alter the carrier risks of about $11 \%$ a mothers of isolated cases. In those families where DMD is associated with deletion of a probe site more accurate counselling of mothers is sometime possible.

As linkage information becomes more accurate, if is hoped that it will allow carrier women to havefamilies without the fear of having an affected child and without the guilt consequent upon the termina tion of pregnancies which could have been normal? However, we remain unable to predict the twe thirds of cases of DMD which present with nơ previous family history.

We gratefully acknowledge the support of th Muscular Dystrophy Group of Great Britain an\& Northern Ireland, and of the Generation Trust. WE also thank $\operatorname{Dr}$ L Kunkel, Dr R Worton, and Professor P Pearson for kindly donating DN probes; Drs B Neville and $\mathrm{R} O \mathrm{O}$ Robinson fot referring patients from Guy's Hospital; Professoक D W Moss and Dr K B Whitaker, of the Royal. Postgraduate Medical School, for CK assays an carrier risk evaluation; Drs $\mathrm{R}$ Sheridan and $\mathrm{N}$

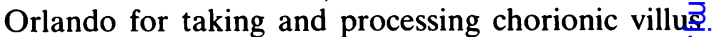
samples at Guy's Hospital; the staff of the Harris Birthright Centre at King's College Hospital fo referring patients, and taking some of the chorionio villus samples; Drs J Old and K Davies for much helpful advice and assistance; and the staff of the Muscle Clinic, Hammersmith Hospital, for provic:ing detailed information on many of the patientsos Lastly, we thank Miss Elizabeth Manners for hero invaluable help in preparing this manuscript.

\section{References}

I Dubowitz V. Muscle disorders in childhood. Major problems clinical pediatrics. Vol 16. Philadelphia: Saunders, 1978:19-6e

2 Shaw RF, Dreifuss FE. Mild and severe forms of X-linked muscular dystrophy. Arch Neurol 1969;20:451-60.

${ }^{3}$ Emery AEH, Skinner R. Clinical studies in benign (Becke type) X-linked muscular dystrophy. Clin Genet 1976;1 189-201.

4 Murphy EA, Mutalik GS. The application of Bayesian metho\& in genetic counselling. Hum Hered 1969;19:126-51. 
'Emery AEH. Carrier detection in sex-linked muscular dystrophy. J Genet Hum 1965;14:318-29.

- Bakker E. Hofker MH, Goor N, et al. Prenatal diagnosis and carrier detection of Duchenne muscular dystrophy with closely linked RFLPs. Lancet 1985;i:655-8.

7 Dubowitz V. Investigation of neuromuscular disorders. J R Coll Physicians Lond 1983:17:134-8.

* Moss DW. Whitaker KB. Parmar C. et al. Activity of CK in sera from healthy women. carriers of DMD and cord blood, determined by the 'European' recommended method with NAC-EDTA activation. Clin Chim Acta 1981:116:209-16.

"Sibert JR, Harper PS. Thompson RJ, Newcombe RG. Carrier detection in Duchenne muscular dystrophy: evidence from a study of obligatory carriers and mothers of isolated cases. Arch Dis Child 1979:54:534-7.

11) Sarfarazi M, Williams H. A computer programme for estimation of genetic risk in $\mathrm{X}$ linked disorders, combining pedigree and DNA probe data with other conditional information. $J$ Med Genet 1986:23:40-5.

1 Kunkel LM, Smith KD, Boyer SH, et al. Analysis of human Ychromosome-specific reiterated DNA in chromosome variants. Proc Natl Acad Sci USA 1977:74:1245-9.

12 Southern EM. Detection of specific sequences among DNA fragments separated by gel electrophoresis. J Mol Biol 1975;98: 503-17.

13 Walker A, Hart K, Cole C, et al. Linkage studies in Duchenne and Becker muscular dystrophies. J Med Genet 1986;23:538-47.

${ }^{14}$ Aldridge J, Kunkel L. Bruns G, et al. A strategy to reveal highfrequency RFLPs along the human X chromosome. Am J Hum Genet 1984:36:546-64

15 Monaco AP. Bertelson CJ, Middlesworth W, et al. Detection of deletions spanning the Duchenne muscular dystrophy locus using a tightly linked DNA segment. Nature 1985:316:842-5

is Ray PN, Belfall B, Duff C, et al. Cloning of the breakpoint of an
$\mathrm{X}: 21$ translocation associated with Duchenne muscular dystrophy. Nature 1985:318:672-5.

17 Hofker MH, Wapenaar MC, Goor N, Bakker E, van Ommen GJB, Pearson PL. Isolation of probes detecting restriction fragment length polymorphisms from $\mathrm{X}$ chromosome-specific libraries: potential use for diagnosis of Duchenne muscular dystrophy. Hum Genet 1985;70:148-56.

is de Martinville B, Kunkel LM, Bruns G, et al. Localisation of DNA sequences in region $\mathrm{Xp} 21$ of the human $\mathrm{X}$ chromosome. Hum Genet 1985;70:249-55.

19 Wieacker P, Davies K, Cooke HJ, et al. Towards a linkage map of the human $\mathrm{X}$ chromosome: regional assignment of 16 cloned single copy DNA sequences employing a panel of somatic cell hybrids. Am J Hum Genet 1984;36:265-76.

20) Williams H, Sarfarazi M, Brown C, Thomas N, Harper PS. The use of flanking markers in prediction for Duchenne muscular dystrophy. Arch Dis Child 1986;61:218-22.

${ }^{21}$ Hart K, Cole C, Walker A, et al. The screening of Duchenne muscular dystrophy patients for submicroscopic deletions. $J$ Med Genet 1986;23:516-20.

22 Pembrey ME, Davies KE. Winter RM, et al. Clinical use of DNA markers linked to the gene for DMD. Arch Dis Child 1984:59:208-16.

${ }^{23}$ Emery AEH, Skinner R, Holloway S. A study of possible heterogeneity in Duchenne muscular dystrophy. Clin Genet 1979;15:444-9.

${ }^{24}$ Rabbi-Bortolini E, Zatz M. Investigation on genetic heterogeneity in Duchenne muscular dystrophy. Am J Med Genet 1986;24:111-7.

Correspondence and requests for reprints to Dr S Hodgson, Paediatric Research Unit, Guy's Hospital Medical School, Guy's Tower 8th Floor, London SE1 9RT. 